\title{
Familial cutaneous telangiectasia and oropharyngeal cancer predisposition syndrome
}

INSERM

\section{Source}

INSERM. (1999). Orphanet: an online rare disease and orphan drug data base. Familial cutaneous telangiectasia and oropharyngeal cancer predisposition syndrome.

ORPHA:313846

Familial cutaneous telang iectasia and oropharyngeal cancer predisposition syndrome is a rare, inherited cancer-predisposing syndrome characterized by an early development of cutaneous telangiectasia, mild dental and nail anomalies, patchy alopecia over the affected skin areas and increased lifetime risk for oropharyngeal cancer. Other types of cancer have also been reported. 